\title{
Periodontal Muscle Training Can Strength the Periodontal Support, Fit Your Teeth
}

\author{
Nima sabzchamanara* \\ Therapeutic Dentistry Department, Ukraine \\ *Corresponding author: Nima sabzchamanara, Therapeutic Dentistry Department, National medical university, Ukraine

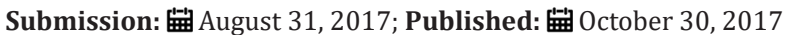

\begin{abstract}
Statistical analysis, A total of 505 patients in general practice were asked to respond to a list of 25 obligatory nourishment for a child while going to have the first teeth, for its effectiveness in dealing with patient's periodontal health especially include chewing hard food. They were also asked to select the three effective nutrition for periodontal tissue. The indicts of patient perceived importance of the periodontal health were derived and each compared with actual effectiveness as determined from a sample of 250 patients opinion. Although the majority of patient's 18 of 25 nutrition as being very effective, there was no significant association with patient perceived nourishment effectiveness and actual effectiveness. The implications for patient training are discussed.
\end{abstract}

\section{Introduction}

By comparing the effect of long term workout in the fitness gyms and the habit of consuming hard rational food daily with a weekly schedule, could be very likely and would be support the oral health indeed. What to do to have aesthetically and functionally prevention method for further gum and periodontal diseases, which could be less aggressive and conservative, cheap and home treating methods. In case one cares about his body's physique, also he can care about the Gum structure as well (Table 1).

Table 1

\begin{tabular}{|c|c|}
\hline EXIRA QUESTIONS & $\begin{array}{c}\text { TOTAL } \\
\text { ADULTS }\end{array}$ \\
\hline $\begin{array}{c}\text { I try to eat healthy these days and pay } \\
\text { attention to nutrition }\end{array}$ & $84.00 \%$ \\
\hline In general I feel I eat right & $60.00 \%$ \\
\hline I try to eat a healthy breakfast daily & $57.00 \%$ \\
\hline I follow a regular exercise routine & $62.00 \%$ \\
\hline I pay attention how many times I chew \\
food & $30.00 \%$ \\
\hline I visit my dentist two times a year & $36.00 \%$ \\
\hline I regularly eat organic food & $32.00 \%$ \\
\hline I prefer to eat at home rather restaurant & $65.00 \%$ \\
\hline
\end{tabular}

Materials and Methods

To have a review, Bundles attached to teeth and their dis attachments provoke further injuries. Let's take a look at these bundles, if we peel away alveolar septa and papillae \& marginal part, we can see the bundles (periodontal ligament), [1] which is composed of bundles of connective tissues fiber that anchor the teeth within the jaw. Each bundle is attached to cementum covering the root of the tooth. The other end is embedded in bony tooth sockets (alveolar socket). These bundles of fibers allow the tooth to withstand the forces of biting and chewing.

\section{Table 2}

$\begin{array}{lc}\text { CHILD'SOBLIGATORY NURISHMENT } & \text { TOTAL ADULT'SINTAKE } \\ \text { CHEESE } & 71 \% \\ \text { YOGURT } & 85 \% \\ \text { LEAFY GREENS } & 45 \% \\ \text { APPLES } & 52 \% \\ \text { ALMONDS } & 45 \% \\ \text { CARROT } & 33 \% \\ \text { CELERY } & 14 \%\end{array}$

Endomysium, the connective tissue sheaths that surround each skeletal muscle fiber separating the muscle cells from one another. It also contains capillary nerves and lymphatics. As an illustration, Organization of skeletal tissues, intact skeletal muscle. Biceps bra chi is attached to bones through tendons. connective tissue. The entire muscle is surrounded by connective tissue called epimysium [2]. The muscle is organized into bundles called premium. Each fascicle contains many individual fibers surrounded by connective 
tissue called Endomysium. In some muscles there might only be relatively few fibers such as in muscle of the eye in which these are only 10 of fibers. In some of the bigger muscles in the body there may be thousands of fibers, for instance, there can be up to 400000 fibers in the bicep muscle in front of the arm. Each of these fibers is surrounded by sheaths of fibrous tissue membrane or fascia called Endomysium (endo-means within). Therefore, by having regular training in fitness centers our extremities muscles can strength and can have an aesthetic and supportive function for skeletal system (Table 2).

\section{Result}

As within skeletal growth, the muscles in the body also grow at irregular rates. The enlargement of muscles (hypertrophy) makes them thicker but muscle fibers can also get longer. With certain types of training and genetics, muscle mass can change [3]. According to the aging of muscular system, one reason is reducing the strength and power of the muscles; therefore, by training the endomysiums within the periodontal ligament with special training as well as eating hard foods and chewing them we can train them exactly like fitness club. The experiment above 18-25\% of those patients who had answered to the test satisfactory had a healthier gum structure in comparing with the unsatisfactory ones. By making some clinics besides gyms and sport centers which prescribe daily, weekly, monthly schedules to fit the gum muscles with special measurement individually for each patient can make a revolution in gum and oral health history [4-7].

\section{Conclusion}

Due to the proper nourishment for the newborn babies we acknowledge that they are effective to form the jaws, gums, teeth, and help them nourish well and form the proper shape. Therefore, repeating this process could be an aid for preventing any lack of support or lease to make further diseases as this nutrition only strength the body mass around teeth.

\section{Acknowledgment}

The author appreciates the CAMLOG for choosing the article for the first time.

\section{References}

1. McGraw-Hill Glossary Anatomy and Physiology A\&P (2001). The McGraw-Hill Companies.

2. Plowman SA, Smith DL (2013) Exercise Physiology for Health Fitness and Performance.

3. Coulson M (2013) The Complete Guide to Personal Training.

4. Laura Beil (2016) Gum disease opens up the body to a host of infections.

5. Fehrenbach M, Bath-Balogh M (2011) Illustrated Dental Embryology, Histology, and Anatomy.

6. Mosby (2009) Mosby's Medical Dictionary. ( $8^{\text {th }}$ edn), Elsevier.

7. Mackenzie, Colin, Paul B Hoeber (1918) Retrieved 18 April 2015, England. 